\title{
Depression Socialization Within Friendship Groups at the Transition to Adolescence: The Roles of Gender and Group Centrality as Moderators of Peer Influence
}

\author{
Christopher C. Conway, \\ Department of Psychology, University of California, Los Angeles \\ Diana Rancourt, \\ Department of Psychology, University of North Carolina at Chapel Hill \\ Caroline B. Adelman, \\ Department of Psychology, University of North Carolina at Chapel Hill \\ William J. Burk, and \\ Behavioral Science Institute, Radboud University Nijmegen, Nijmegen, The Netherlands \\ Mitchell J. Prinstein \\ Department of Psychology, University of North Carolina at Chapel Hill
}

\begin{abstract}
Tests of interpersonal theories of depression have established that elevated depression levels among peers portend increases in individuals' own depressive symptoms, a phenomenon known as depression socialization. Susceptibility to this socialization effect may be enhanced during the transition to adolescence as the strength of peer influence rises dramatically. Socialization of depressive symptoms among members of child and adolescent friendship groups was examined over a 1-year period among 648 youth in grades six through eight. Sociometric methods were utilized to identify friendship groups and ascertain the prospective effect of group-level depressive symptoms on youths' own depressive symptoms. Hierarchical linear modeling results revealed a significant socialization effect and indicated that this effect was most potent for (a) girls and (b) individuals on the periphery of friendship groups. Future studies would benefit from incorporating child and adolescent peer groups as a developmentally salient context for interpersonal models of depression.
\end{abstract}

\section{Keywords}

depression; socialization; friendship group; peer influence; adolescence

\begin{abstract}
Building on established cognitive-interpersonal models of depression (Hammen, 1992; Joiner \& Coyne, 1999), recent research has focused on understanding developmental variation in social processes implicated in the onset and maintenance of depression (e.g., Hankin, Mermelstein, \& Roesch, 2007; Rudolph \& Hammen, 1999). Accumulating data suggest that the transition to adolescence is a period of heightened vulnerability to depressogenic interpersonal contexts, particularly for girls (Hankin \& Abramson, 2001; Rudolph, Flynn, \& Abaied, 2008). The current study applies a developmental perspective to
\end{abstract}

\footnotetext{
(C) 2011 American Psychological Association

Correspondence concerning this article should be addressed to Christopher C. Conway, Department of Psychology, Box 951563, UCLA, Los Angeles, CA 90095-1563. conwayc@ucla.edu.
} 
the transmission of depressive symptoms within social networks. Specifically, we examine the tendency for youths' depressive symptom levels to become more similar to fellow peer group members' symptom levels over time, a phenomenon known as depression socialization (Hogue \& Steinberg, 1995). In addition, we investigate developmental factors controlling susceptibility to socialization.

Depression socialization initially was documented in the adult clinical literature, with much of the relevant research deriving from Coyne's (1976a) interpersonal theory of depression. Coyne postulated that dysphoric individuals induce negative affect in significant others, eventually leading to rejection and worsening depression. Although the idea of depression socialization represents only an intermediary step in a larger etiological model (Coyne, 1976a), it has generated a considerable amount of research in its own right. Early experimental tests of the socialization hypothesis found that, relative to participants encountering nondepressed controls, participants who had phone conversations with depressed outpatients (Coyne, 1976b) and brief social interactions with depressed confederates in the laboratory (Hammen \& Peters, 1978; Marks \& Hammen, 1982) reported elevated levels of depressed affect.

Subsequent investigations have examined the depression socialization hypothesis in naturalistic social contexts. For instance, studies examining the intergenerational transmission of depression have reported a temporal association between mother and child depression diagnoses such that offspring depressive symptoms varied in synchrony with fluctuations in maternal symptoms (Abela, Zinck, Kryger, Zilber, \& Hankin, 2009; Hammen, Burge, \& Adrian, 1991; Radke-Yarrow, Nottelman, Belmont, \& Welsh, 1993). Similarly, sociological data from the Framingham Heart Study (Dawber, 1980) revealed that sadness and loneliness reported by adults' distal social network ties significantly predicted adults' own internalizing distress over time (Cacioppo, Fowler, \& Christakis, 2009;

Rosenquist, Fowler, \& Christakis, 2010). Notably, females were especially susceptible to the spread of loneliness and depressive symptoms within their social networks.

\section{The Peer Environment as a Context for Socialization}

Compared with the study of depression socialization in adults, relatively little research has examined the socialization of depressive symptoms among peers in childhood and adolescence. The lack of research examining peer group influences on youths' depressive symptoms is somewhat surprising in light of abundant developmental and clinical child research that offers a strong rationale for the salience of the peer context. It is interesting to note that the same developmental period associated with dramatic increases in the prevalence of adolescents' depressive symptoms also is associated with multiple adaptations in adolescents' peer experiences (Brown, 1990; Hankin et al., 1998). For instance, prior work has suggested that the adolescent transition period is associated with considerable increases in youths' time spent with peers as compared with parents (Larson, Richards, Moneta, Holmbeck, \& Duckett, 1996). Through processes of reflected appraisal and social comparison, peer experiences are used as the basis for adolescents' identity development (Furman \& Buhrmester, 1992; Harter, 1990; Harter, Stocker, \& Robinson, 1996). The peer context also provides an opportunity to experiment with new social roles and more autonomous relationship behaviors (e.g., disclosure, emotional intimacy) at the adolescent transition (Buhrmester, 1990; Hartup, 1996).

These functional changes in the peer environment at the adolescent transition are theorized to magnify the effect of peer behavior on youths' own adjustment (e.g., Brown, Clasen, \& Eicher, 1986). Substantial research has suggested that this developmental period is associated with a marked increase in susceptibility to peer conformity and influence 
processes (e.g., Steinberg \& Monahan, 2007; Steinberg \& Silverberg, 1986). Indeed, peer influence effects have been demonstrated remarkably consistently for child and adolescent externalizing and health risk behaviors, such as aggression (Cohen \& Prinstein, 2006; Ellis \& Zarbatany, 2007), alcohol and substance use (Bot, Engels, Knibbe, \& Meeus, 2005; Mounts \& Steinberg, 1995; Poelen, Engeles, Van der Horst, Scholte, \& Vermulst, 2007), delinquency (Burk, Steglich, \& Snijders, 2007; Vitaro, Brendgen, \& Tremblay, 2000), and weight-management behavior (Hutchinson \& Rapee, 2007; Paxton, Schutz, Wertheim, \& Muir, 1999).

To date, research examining peer influence of internalizing symptoms has been extremely limited, relative to the wealth of evidence supporting peer influence of externalizing behaviors (Hogue \& Steinberg, 1995). However, some recent work has found evidence of socialization of adolescent depressive symptoms within the context of a best friendship (Giletta et al., in press; Prinstein, 2007) or multiple friendship ties (Van Zalk, Kerr, Branje, Stattin, \& Meeus, 2010). Consistent with theories offered by Coyne, Joiner, and others (see Joiner \& Coyne, 1999), data have suggested that a very best friend's level of depressive symptoms is associated with increases in adolescents' own depressive symptoms and depressogenic cognitions over time (Giletta et al., in press; Prinstein, 2007; Stevens \& Prinstein, 2005). Van Zalk and colleagues (2010) considered adolescents' depression socialization within multiple friendship ties using SIENA (Snijders, 2001), a statistical program that allows for simultaneous analysis of peer selection, influence, and de-selection processes in friendship networks. These authors found that multiple peers within an individual's network may independently exert an influence on youths' depressive behavior even after accounting for selection effects (Van Zalk et al., 2010).

The present study extends this prior research by examining depression socialization within groups of peers that spend time together. The focus on larger, interaction-based peer groups is relevant for three reasons. First, developmental research strongly indicates that early adolescent dyadic friendships typically occur within a larger friendship group, or "clique" (e.g., Bagwell, Coie, Terry, \& Lochman, 2000). Indeed, isolated dyads of early adolescent friends are quite rare; even very best friendship interactions typically occur within a larger friendship group of interconnected peers (Bagwell et al., 2000; Urberg, Degirmencioglu, Tolson, \& Halliday-Scher, 1995).

Second, cliques possess norms, rules, and a hierarchy that have a unique potential for influence beyond the effects of a series of independent dyadic ties (Adler \& Adler, 1998; Corsaro \& Eder, 1990; Wasserman \& Faust, 1994). In other words, friendship groups constitute local peer cultures that may be particularly effective conduits for socialization of attitudes and behaviors at the adolescent transition. Third, empirical data indicate that dyadic best friendships only are moderately stable over time; indeed, the majority of youth are likely to select a different "best friend" within a 6-month period, particularly at the adolescent transition (e.g., Degirmencioglu, Urberg, Tolson, \& Richard, 1998). In contrast, data suggest that the composition of the friendship group (i.e., clique) is comparatively more stable (Degirmencioglu et al., 1998). Thus, the potential influence of a friendship group is especially important to examine to gain a better understanding of enduring influences on youths' depressive symptoms.

Unfortunately, neither Prinstein and colleagues (Prinstein, 2007; Stevens \& Prinstein, 2005) nor Van Zalk et al. (2010) examined friendship groups specifically. Although the SIENA program utilized by Van Zalk and colleagues offers an opportunity to examine multiple friendship ties simultaneously, this procedure does not allow for the conceptualization or measurement of a friendship group, the measurement of group norms, or one's position 
within a friendship group. Thus, the impact of a specific friendship group on depressive symptoms has yet to be examined.

\section{Present Study}

The presgent study expands on past depression socialization research in several conceptual ways. First and most importantly, this study examines the longitudinal influence of a specific friendship group on youths' depressive symptoms. Using social network analysis of peer nomination data to identify specific friendship groups, the average level of depressive symptoms within friendship groups is examined as a predictor of youths' own depressive symptoms over a one year interval. It is important to note that data are collected from a community sample of children and adolescents at the critical developmental transition associated with increased vulnerability to depression (Hankin \& Abramson, 2001; Twenge $\&$ Nolen-Hoeksema, 2002). Thus, this study allows for examination of a peer influence effect that may contribute to the development of depressive symptoms, with implications for understanding depression onset at the transition to adolescence and perhaps also the emergence of gender differences in depressive symptoms during this period.

Second, multiple informants are utilized to determine friendship groups as well as participants' depressed affect. Given known biases in youths' estimations of their peer relationships (Zakriski \& Coie, 1996) and their estimations of their friends' attitudes and behaviors (Prinstein \& Wang, 2005), it is essential that data used to examine peer influence rely on external informants. In this study, socialization hypotheses are tested using both peer- and self-report measures of depressive symptomatology as a means of examining the robustness of the socialization effect across different indices of depressive behavior.

Third, this study offers an important contribution to the social development literature, by elucidating factors that may moderate youths' susceptibility to socialization effects (Brechwald \& Prinstein, 2011). Given the remarkable difficulties associated with dissuading youth from befriending peers who may exert deleterious influences, recent research has focused on factors that may be associated with vulnerabilities to peer influence. Such factors could be the target of prevention efforts or could be used to help identify those who may be most likely to fall prey to peer influence. Following from theories and findings in ethnography and developmental psychology research, this study examines youths' position within their friendship group hierarchy as a moderator of depression socialization (Cairns, Leung, Buchanan, \& Cairns, 1995; Eder, 1985; Lansford, Killeya-Jones, Miller, \& Costanzo, 2009). Prior work, however, supports competing hypotheses. Some research has suggested that central or nuclear members of child and adolescent friendship groups may be most susceptible to group influences given that these members are most frequently exposed to social norms among all group members (Urberg, Luo, Pilgrim, \& Degirmencioglu, 2003). Other research has suggested that less central (i.e., peripheral) members are most susceptible to group influences, based on the hypothesis that these members may adopt group norms to earn more favorable positions within the group (e.g., Lansford et al., 2009). As a result, we do not make specific predictions regarding how socialization may vary according to centrality to the friendship group network.

It also is predicted that gender will serve as a moderator of the depression socialization effect. As noted above, adult sociological data indicate that women may be more heavily influenced by internalizing distress in their extended social network (Cacioppo et al., 2009). Furthermore, research investigating the etiological role of interpersonal stressors in adolescent depression has suggested that girls are more susceptible to the depressogenic effects of disturbances in interpersonal relationships (Rudolph, 2002; Rudolph \& Hammen, 
1999; Shih, Eberhart, \& Hammen, 2006). In line with this prior work, we hypothesize that peer influence of depressive symptoms will be particularly strong among girls.

\section{Method}

\section{Participants}

Participants included 648 children and adolescents (49\% female) in Grades 6 (36.3\%), 7 $(30.1 \%)$, and $8(33.6 \%)$ at the outset of the study. The ethnic composition of the sample included 84.4\% White/Caucasian, 1.4\% African American, 4.2\% Asian American, 1.9\% Latino American, and $5.9 \%$ of participants from mixed ethnic backgrounds (2.3\% did not report their ethnic backgrounds). Participants were age 10 (1.1\%), 11 (28.5\%), $12(28.2 \%)$, 13 (31.9\%), and $14(6 \%)$ at Time 1 (two individuals did not report their date of birth). Participants were enrolled in public schooling within a city of fairly homogeneous middleclass socioeconomic status. According to neighborhood and school records, average adult per capita income was approximately $\$ 30,220$, and $11 \%$ of children were eligible for free or reduced-price lunch.

\section{Procedure}

At Time 1, all 6th to 8th grade students from a single middle school were mailed and handdistributed consent forms for study recruitment with strong encouragement and incentives for consent form return. Incentives included entry into a drawing for several small prizes (i.e., movie passes) and a grand prize (i.e., Sony Playstation), as well as individual incentives (i.e., a candy bar) for each student who returned a consent form (regardless of whether parents granted or denied consent). Teachers also received prorated financial incentives based on the proportion of their students who returned forms. Overall, consent forms were returned by $92 \%$ of families $(n=784)$; of these, $83 \%$ of parents gave consent for their child's participation, yielding a consented sample of 648 participants at Time 1 (76\% of the total population). Youth provided assent at the start of the study. A total of 579 (91\%) of these participants completed testing approximately 1 year later (i.e., Time 2), when students were in Grades 7-9. A 1-year longitudinal interval was used to allow time for hypothesized socialization processes to occur, to yield sufficient time for changes in depressive symptoms, and to ensure that both data collections occurred at comparable times during the academic year. Attrition was attributable to participants' moving away from the area $(n=36)$, absenteeism or invalid data $(n=24)$, and refusal to continue participation $(n=$ $5)$.

Sociometric nominations-Peer nomination procedures sometimes involve nomination rosters that include only consented study participants, and other times rosters that include the entire peer group. The human subjects committee and school personnel involved in this project believed that the omission of unconsented participants on the nomination roster may inappropriately call attention to nonparticipants. Thus, it was recommended that grade-wide rosters, including all school peers, be included in sociometric procedures. Students in this school were organized into academic teams, each roughly twice the size of a traditional academic classroom; adolescents were each presented with alphabetized rosters of all academic teammates and were asked to select an unlimited number of peers for two sociometric items (described below). The order of the alphabetized names on each roster was counterbalanced (e.g., Z through A) to control for possible effects of alphabetization on nominee selection.

\section{Measures}

Depressive symptoms-At Time 1 and Time 2, participants completed the Children's Depression Inventory (CDI; Kovacs, 1992), a 27-item measure assessing the behavioral, 
cognitive, emotional, and physiological features of depression. The CDI has been validated for use with youth between the ages of 7 and 18 years (Kazdin, 1990). Using a three-item response format to capture low endorsement, moderate endorsement, and high endorsement of depressive symptoms (e.g., $0=I$ am sad once in a while; $1=I$ am sad many times; $2=I$ am sad all the time), participants endorsed statements best describing their level of depressive symptoms in the previous two weeks. A total score was computed, with higher scores indicating higher levels of depressive symptoms. Kovacs (1992) recommended cutoffs of either 12 or 19 (depending on the need to minimize false negatives or false positives) to indicate clinically significant levels of depressive symptoms. According to these standards, $11.80 \%$ or $3.70 \%$ of youth in our sample were experiencing clinically meaningful levels of depression at Time 1 . The CDI has been reported to be a reliable and valid index of depressive symptom severity (Saylor, Finch, Spirito, \& Bennett, 1984). In the present sample, Cronbach's alpha for the CDI was 0.89 at both Time 1 and Time 2.

Sad affect-Sociometric peer nominations were conducted to obtain a measure of participants' peer-perceived sadness at both time points. Students nominated an unlimited number of peers who "looked sad and unhappy most of the time." Because all individuals on the class roster could be nominated, scores of peer-perceived sadness were calculated for all individuals who received nominations. A standardized total of nominations received by each student within his or her academic team was computed, regardless of participation status. As with all standardized scores, average scores for the sample were 0 , positive scores indicated greater sad affect than average, and lower scores indicated lower sad affect than average.

The means and $S D$ s reported in Table 1 differ from 0 and 1, respectively, because of the fact that not all students in the standardization sample (i.e., the entire school) participated in this study. Peer nomination measures often have been used to obtain an index of peer-perceived sadness (e.g., Cole \& Carpentieri, 1990). This approach yields data that traditionally are correlated moderately with self- and teacher-reported measures of depressive symptoms (Cole \& Carpentieri, 1990; Lefkowitz \& Tesiny, 1984, 1985).

Friendship groups-At Time 1, participants identified an unlimited number of their "closest friends" from alphabetized rosters of all academic teammates. This peer nomination measure is similar to prior research examining child and adolescent friendship affiliations (Parker \& Asher, 1993). Nominations at Time 1 were used to identify peer groups within the friendship networks of each academic team. Peer groups were determined by initially identifying all friendship groups (overlapping subgroups of at least three individuals who all nominate one another) and then analyzing the overlap between groups with a hierarchical clustering algorithm (single-link) to classify individuals into nonoverlapping peer groups (Everett \& Borgatti, 1998). Peer groups derived from hierarchical clustering methods have been found to produce similar groupings as those found using principal components and social- cognitive mapping methods (Rodkin \& Ahn, 2009).

The "clique" routine in UCINET version 6.145 (Borgatti, Everett, \& Freeman, 2002) detected a total of 1306 friendship groups in the 6th grade (ranging from 3 to 10 members; $M=4.33, S D=1.39$ ), 1290 friendship groups in the 7th grade (ranging from 3 to 7 members; $M=4.16, S D=1.03$ ), and 1133 friendship groups in the 8th grade (ranging from 3 to 8 members; $M=4.26, S D=1.16$ ). Hierarchical cluster analyses categorized individuals into nonoverlapping peer groups by aggregating pairs of individuals with the most overlap in group membership. A total of 89 groups were yielded by this procedure: 33 groups in Grade 6 (ranging from 3 to 28 members; $M=9.8, S D=7.4$ ); 28 groups in Grade 7 (ranging from 3 to 30 members; $M=10.3, S D=7.7$ ); and 28 groups in Grade 8 (ranging from 3 to 25 members; $M=9.8, S D=5.7)$. Of these 89 groups, 67 groups were same-gender friendship groups (75\%), and 25 of these groups were all-female (37\%). The 6th grade had the highest number of same-gender friendship groups (26), followed by the 7th grade (23), and then the 
8th grade (18). A total of 11 students did not belong to any friendship groups ( $n=4$ in Grade 6, $n=4$ in Grade 7, and $n=3$ in Grade 8) and were therefore omitted from socialization analyses.

Individual membership in each peer group was cross-validated by performing additional subgroup analyses using the factions routine in UCINET (for details, see Hanneman \& Riddle, 2005). The two methods produced similar groupings in each grade. We present results using the hierarchical clustering method. An identical pattern of statistically significant results were obtained from data using the peer groups yielded from factions analyses.

Centrality within the friendship group-Social position within their friendship group was determined by calculating the proportion of friendship nominations received by group members. For each participant, the number of nominations received within his or her identified group was summed, and then divided by the total number of possible nominations a participant could have received from that group (e.g., a participant could receive a maximum of four nominations in a group of five individuals). Higher proportions (i.e., more within-group friendship nominations) indicated higher group centrality. If data were missing for some members of the group, centrality was computed among the remaining members for whom nomination data were available.

\section{Group-level depressive symptoms and peer-perceived sadness-Data from} each peer group member were used to compute an average level of depressive symptoms and peer-perceived sadness for each group at Time 1. It is important to note that these scores used participants' peers' own reports of their depressive symptoms and peer-reported sad affect for each group member to assess the levels of depressive symptoms and peerperceived sadness, respectively, within each participant's friendship group. Thus, data on group-level variables were based on independent informants, and were not methodologically influenced by participant's own report of depressive symptoms. In addition, group mean scores were computed separately for each member of a specific group. In other words, each participant's own scores were omitted from computations of group mean values, yielding measures of average depressive symptoms and peer-perceived sadness among groupmates that did not overlap with youths' own scores, and varied even among members of the same group.

\section{Data Analytic Procedures}

The study of individuals nested within groups is best suited to a hierarchical linear modeling (HLM) approach (Snijders \& Bosker, 1999). Two-level models were estimated to determine the effect of Time 1 friendship group depressive symptoms on participants' own levels of depressive symptoms at Time 2. Separate models were estimated for the two different operationalizations of depressive behavior: self-reported CDI and peer-rated sad affect. In one model, group mean CDI levels at Time 1 were used to predict youth CDI at Time 2, controlling for youth CDI at Time 1. In the other model, group mean peer-perceived sadness at Time 1 was used to predict youths' own peer-perceived sadness at Time 2, controlling for youths' peer-perceived sadness at Time 1 .

Level-1 predictors in these models included gender, age, centrality in the friendship group at Time 1, youths' CDI and peer-rated sadness at Time 1, and group mean CDI and peer-rated sadness at Time 1 . All variables were grand-mean centered with the exception of centrality, which was centered within groups. It is important to note here that group mean predictors were conceptualized as level-1 variables because, as noted above, group means were computed while omitting the participant's own score. As such, it was possible for group 
mean CDI scores and peer-perceived sadness to vary across members of the same friendship group.

Although there were no between-groups (level-2) predictors in the current analyses, a twolevel (level-1 = individuals; level-2 = peer groups) approach was still considered appropriate given the nested structure of the data. That is, standard regression methods can produce misleading results because they require assumptions about the independence of errors that are frequently violated when individuals are clustered within groups (Raudenbush \& Bryk, 2002). Nontrivial intraclass correlation values (see Results) suggested within-group dependence of observations in both models, recommending a HLM approach.

After examining the primary socialization hypothesis, predictions regarding moderation of socialization by gender and centrality within the friendship group were tested by adding corresponding interaction terms to the level-1 model. Two-way interaction terms representing the product of gender and centrality with initial group mean depressive symptom levels were entered simultaneously to obtain their unique effects on subsequent depression outcomes. Significant interactions were interpreted following the guidelines offered by Aiken and West (1991). Simple slopes were calculated to examine the strength of socialization across gender and at $1 S D$ above and below the mean of the continuous centrality variable.

There were 44 participants missing Time 2 peer-rated sad affect ( $93 \%$ retention) and 69 participants missing Time 2 CDI scores (90\% retention). Although it is impossible to establish that data are missing at random (MAR; Potthoff, Tudor, Pieper, \& Hasselblad, 2006), small correlations between Time 1 sad affect and depressive symptoms and missingness on these same measures at Time $2(\mathrm{Is}<.10)$ were suggestive of MAR for these Time 2 markers. Thus, Empirical Bayesian estimates for missing data generated in HLM 6 (Raudenbush, Bryk, Cheong, \& Congdon, 2004) were deemed appropriate and used for all analyses.

\section{Results}

Correlations and descriptive statistics for all study variables are presented in Table 1.

Moderate correlations between indicators of Time 1 (T1) friendship group depression and indicators of Time 2 (T2) youth depression were suggestive of a socialization effect. Moderate correlations between CDI and peer-rated sadness ( $I \mathrm{~s}=.25$ at T1 and .18 at T2) supported a conceptualization of these two variables as related, but not redundant, indices of depressive behavior.

\section{Examination of Depression Socialization}

Self-reported CDI-As a preliminary step, a fully unconditional model was estimated to ascertain the proportion of variance in T2 CDI that was attributable to between-groups differences. The intraclass correlation (ICC) from this analysis indicated that $13.63 \%$ of the variance in the outcome was between-groups, indicating that HLM was an appropriate analytic strategy. On level-1, age, $b=0.39, t(87)=3.63, p=.001$, and T1 youth CDI, $b=$ $0.62, t(87)=16.85, p<.001$, were strong predictors of T2 youth CDI score, whereas gender, $b=0.21, t(87)=0.87, p=.39$, and centrality, $b=0.16, t(87)=0.18, p=.85$, did not exert significant main effects. Most important, consistent with the socialization hypothesis, CDI levels in friendship groups at T1 were related prospectively to youths' own CDI at T2 in the predicted direction, $b=0.20, t(87)=2.88, p<.01$.

Peer-perceived sad affect-The ICC from the unconditional model indicated that approximately $61.01 \%$ of the variance in $\mathrm{T} 2$ peer-rated sadness was between-groups. The 
effects of gender, $b=0.07, t(87)=1.25, p=.21$; centrality, $b=0.10, t(87)=0.81, p=.42$; and age, $b=-0.02, t(87)=-0.82, p=.42$, did not significantly differ from 0 , whereas the prospective influence of individuals' $\mathrm{T} 1$ peer-rated sadness was relatively large and significant, $b=0.45, t(87)=7.37, p<.001$. Consistent with the CDI model, mean levels of peer-perceived sadness within the friendship group at $\mathrm{T} 1$ had a significant longitudinal effect on peer ratings of participants' own sadness, $b=0.33, t(87)=3.60, p<.001$, supporting the general hypothesis of socialization of depressive behavior in the friendship group.

\section{Moderating Roles of Gender and Centrality}

Self-reported CDI-As noted earlier, the product terms representing the two interactions were entered simultaneously into the main effects model, thus partialing out the variance shared between them and providing a more stringent test of each effect. The interaction of mean friendship Group CDI levels at $\mathrm{T} 1$ and gender was a significant predictor of selfreported CDI at T2, $b=0.13, t(87)=2.35, p<.05$. The form of this interaction is depicted on the left side of Figure 1. Supporting the hypothesis that girls would be more susceptible to peer influence of depressive behavior, elevations in T1 group-level depressive symptoms led to more pronounced increases in CDI over time for girls, $b=0.24, t(87)=2.16, p<.05$, relative to boys, $b=0.13, t(87)=1.20, p=.23$. The interaction of centrality and group-level CDI was also a significant predictor of T2 youth CDI, $b=-0.30, t(87)=-2.49, p<.05$. The negative coefficient of the product term indicated that depressive symptoms within the friendship group had the greatest influence on T2 CDI for those who were least central to the peer group. As illustrated on the left side of Figure 2, those at $1 S D$ below the mean on centrality, $b=0.21, t(87)=2.21, p<.05$, showed more change in T2 CDI in response to elevations in group-level CDI than those at $1 S D$ above the mean, $b=0.15, t(87)=1.37, p$ $=.17$. Exploratory analyses revealed no moderation between age and any main effect or two-way interaction in the model; furthermore, no three-way interaction between gender, centrality, and group mean CDI was detected (all $p \mathrm{~s}>.10$ ).

Peer-perceived sad affect-Results from the peer-rated sad affect model revealed a significant gender difference in the association between group-level sad affect and peer ratings of individuals' own sad affect over time, $b=0.48, t(87)=3.80, p<.01$. Again, consistent with predictions, the prospective effect of friendship group sadness on youths' own sadness was more pronounced for girls, $b=0.70, t(87)=4.04, p<.001$, relative to boys, $b=0.20, t(87)=1.75, p=.08$ (Figure 1 ). In line with the CDI model, a significant interaction emerged between level of centrality within the friendship group and group mean levels of peer-rated sadness, $b=-0.50, t(87)=-2.72, p<.01$. As shown on the right side of Figure 2, elevations in groupmates' peer-rated sad affect predicted increases in youths' own peer-rated sadness most strongly among those who had more peripheral standing in the friendship group. Greater change was observed for those at $1 S D$ below the mean on centrality, $b=0.85, t(87)=4.11, p<.001$, compared with those at $1 S D$ above the mean, $b=$ $0.24, t(87)=2.25, p<.05$. Age was not a significant moderator of any main effect or interaction, and again no three-way interaction between gender, centrality, and peer-rated sadness was detected (all $p s>.10$ ).

\section{Discussion}

Interpersonal theories of depression have generated a wealth of research on how depressionprone individuals shape, and are shaped by, their social environments. Recent work exploring developmental variation in depressogenic interpersonal relationships suggests that the transition to adolescence may be a period of heightened interpersonal risk for depression (Hankin \& Abramson, 2001; Rudolph et al., 2008; Rudolph \& Hammen, 1999). Despite 
widespread recognition that interactions among members of peer groups are key determinants of adjustment during this period (e.g., Brown, Eicher, \& Petrie, 1986), prior research has not examined the socialization of depressive symptoms in the friendship group context.

Results supported the existence of a depression socialization effect whereby average levels of depressive symptoms in the friendship group predicted youths' own depressive symptoms over time. It is important to note that this result held even when controlling for youths' initial depressive symptoms, indicating a unique socialization effect above and beyond the possible influences of friendship selection (i.e., assortative pairing) processes (Kandel, 1978). Furthermore, the robustness of the socialization phenomenon was supported by the fact that this effect was observed for both self- and peer-reports of depressive behavior. This finding is consistent with an emerging literature documenting depression socialization in relationship dyads (see Joiner \& Katz, 1999, for a review) and among multiple social ties (Rosenquist et al., 2010; Van Zalk et al., 2010).

The current study extended past efforts by applying a developmental perspective to the socialization theory, which was initially formulated to understand the origins of adult depression (Coyne, 1976a). In line with an extensive literature establishing the increased frequency and salience of peer experiences at the adolescent transition, we hypothesized that friends' depressive symptom levels would be important predictors of youths' own adjustment over time. The friendship group, in particular, was thought to be a potent context for peer influence in light of prominent social norms characterizing these local peer cultures (e.g., Corsaro \& Eder, 1990). Compared with other peer contexts that could be used to examine socialization (e.g., best friendship dyads, entire peer network), friendship groups capture a relatively wide breadth of peer influence processes acting on children and adolescents and, at the same time, exclude noninfluential peer relationships likely to dilute peer influence effects. Locating the depression socialization phenomenon within this group context may aid in understanding social factors that determine risk and resilience to depression in early adolescence. Findings from the current study raise the possibility that socialization within friendship groups with higher depressive symptom levels may contribute to depression vulnerability in early adolescence. Conversely, membership in groups with predominantly nondepressed peers may buffer youth from numerous other risk processes operating during this developmental stage (Hankin \& Abramson, 2001).

Results were obtained within a sample of youth at the transition to adolescence, and socialization effects resembled patterns found within other peer contexts among older adolescents and adults (e.g., Joiner \& Katz, 1999). An important direction for further research will be the examination of possible developmental variation in the magnitude of depression socialization effects, and in the peer contexts in which these effects are most salient. It may be that peer groups are especially relevant depression socialization contexts in late childhood and early adolescence, as this is a primary context in which peer interactions occur at this developmental stage (Urberg et al., 1995). As emotional intimacy and disclosure increase across development, however, depression socialization may be most likely within close dyadic friendships and romantic relationships. Systematic examination of developmental differences in depression socialization effects is sorely needed.

Regarding moderators of peer influence, youths' position within the peer group hierarchy was found to predict the strength of depression socialization. Socialization effects were greatest for youth who were more peripheral (i.e., received fewer friendship nominations from fellow group members) in the peer group. This result is in agreement with previous research showing that peer group centrality is inversely related to conformity to friends' deviant behavior (Lansford et al., 2009). This effect may be driven by the motivation of less 
central group members to adopt group norms so as to improve their status within the group (Crandall, 1988). Following this logic, it is possible that more nuclear members experience less pressure toward conformity with group-sanctioned behavior, leading to increased resilience to depression socialization in groups with high mean depression levels.

It should be noted that prior research on the impact of centrality on vulnerability to socialization has produced divergent results. A number of studies have found children and adolescents with more reciprocated friendships in the peer network to display greater conformity to friends' substance use behavior (Aloise-Young, Graham, \& Hansen, 1994; Urberg et al., 2003), possibly owing to greater exposure to peers' attitudes and behaviors among those central to the peer network (Urberg et al., 2003). More research is needed to clarify whether the effect of centrality on vulnerability to socialization varies depending on the qualities or functions of behaviors being transmitted between peers, or on developmental factors. The present results provide an initial indication that youth on the periphery of peer groups may be most susceptible to peer influence of internalizing symptoms.

Finally, we tested the hypothesis that peer influence effects would be stronger for females as compared with males. Results indicated that girls were indeed more susceptible to socialization within the friendship group. That is, elevated baseline depression levels in the peer group were associated with greater increases over time in depressive symptoms for girls. Gender differences in socialization were hypothesized on the basis of previous research suggesting that adolescent girls display greater depressive reactivity to disturbances in peer relations (Rudolph, 2002; Rudolph \& Hammen, 1999; Shih, Eberhart, \& Hammen, 2006) and data from the Framingham Heart Study indicating that adult women are more influenced by internalizing distress in their extended social network (Cacioppo et al., 2009). It appears that this pattern may extend to socialization within peer groups at the adolescent transition, although this result requires replication.

Whereas current results provided insight into individual differences in vulnerability to peer influence of depressive symptoms, one limitation of the study was that the exact mechanisms of socialization were not addressed. A number of interpersonal processes have been proposed to account for the longitudinal association between group-level depression and youths' own depression, including negative feedback seeking (Joiner, 1995; Swann, Wenzlaff, \& Tafarodi, 1992), excessive reassurance seeking (Coyne, 1976b; Joiner \& Katz, 1999), and corumination (Rose, 2002; Rose, Carlson, \& Waller, 2007). Coyne (1976b) specifically posited that dysphoric individuals induce negative affect (and subsequent interpersonal rejection) in significant others via repetitive pleas for reassurance. Several investigations have demonstrated that excessive reassurance seeking is associated prospectively with increases in depressive symptoms in adolescence (Abela et al., 2005; Joiner, 1999; Prinstein, Borelli, Cheah, Simon, \& Aikins, 2005). Corumination may also be particularly relevant to depression risk during this developmental period, given elevations in intimacy and self-disclosure in peer relations at the transition to adolescence (Buhrmester \& Furman, 1987). Corumination has been posited to affect liability to depression particularly in girls (Rose, 2002), and thus may contribute to gender differences in the strength of socialization.

Several other limitations of the current study may be important in guiding future research. First, whereas this study is consistent with prior investigations demonstrating the socialization of depressive symptoms, it is unclear whether results generalize to interpersonal transmission of depression diagnoses. Also, as approximately $5 \%$ to $10 \%$ of this community sample of youth was experiencing potentially clinically relevant levels of depressive symptoms (Kovacs, 1992), future studies are needed to examine the strength of symptom socialization among populations with consistently elevated levels of depression. 
Furthermore, although socialization effects may account for the initiation of depressive behaviors (e.g., negative affect, depressotypic cognitions), future investigations should examine additional social-psychological systems underlying the escalation from depressive symptoms to syndromal depression. Second, the current study examined only two potential moderators of peer socialization (i.e., gender and centrality in peer group). Future research is needed to investigate the moderating effects of numerous other attributes of both individuals (e.g., social anxiety, self-esteem, attachment cognitions) and friendship groups (e.g., friendship quality and reciprocity) that have been identified previously in the peer influence literature (Prinstein, 2007; Urberg et al., 2003; Vitaro et al., 2000).

An important limitation of this study that will deserve attention in future research pertains to the stability of peer groups over time, and an examination of the "dose" of exposure necessary for depression socialization to occur. An untested, but logical hypothesis suggests that socialization within peer groups is likely dependent on the duration of youths' exposure to attitudes and behaviors of peer group members. Although past research suggests that peer groups remain relatively stable over time, particularly at this developmental period (i.e., approximately $60 \%$ of adolescent friendship group members will remain together over a 1year interval; Degirmencioglu et al., 1998), recent research suggests that children and adolescents with elevated depressive symptoms may be particularly vulnerable to a decrease in the number of their dyadic friendship ties (Van Zalk et al., 2010). These recent findings might have implications for understanding youths' positions within friendship groups. Although currently unknown, it may be that youths' higher levels of depressive symptoms increase the likelihood of movement from central to peripheral positions within their peer groups over time, or possibly to an exclusion from peer groups altogether. Examining the extent to which depressive symptoms are associated with status or membership within a peer group will be an important next step for research in this area. Similarly, it will be important to investigate the length of exposure necessary to promote depression socialization. Results in this study suggested that a one year period is sufficient to observe socialization effects within friendship groups. However, it is unknown whether depression socialization may occur over shorter or longer periods of time, and whether the duration of effects may vary across development.

The current results may have implications for intervention research among youth at risk for depression. First, the socialization finding underscores the importance of the peer group as a target for intervention in early adolescence, as depressive symptoms of one group member may portend maladjustment for peers (Gifford-Smith, Dodge, Dishion, \& McCord, 2005). Second, findings indicated that more peripheral group members had a greater likelihood of displaying depressive responses to groupmates' depressive behavior. This result suggests a need for further research to examine the effects of symptomatic improvement in one group member on other youth in the peer group. It is possible that treatment of youth central to their respective peer groups may accrue benefits for more peripheral groupmates (MillerJohnson \& Costanzo, 2004).

In conclusion, this study attempted to advance our knowledge of the interpersonal origins of depression at the adolescent transition by testing a model of peer socialization of depressive symptoms within friendship groups. The prevalence of depressive symptoms among fellow group members significantly predicted individuals' own symptoms over a one year period. This socialization was strongest for youth with more peripheral positions in the peer group and for girls. Future research on peer influence would benefit from incorporating the friendship group as a level of analysis relevant to understanding interpersonal transmission of depression among youth. 


\section{References}

Abela JRZ, Hankin BL, Haigh EAP, Vinokuroff T, Trayhern L, Adams P. Interpersonal vulnerability to depressive episodes in high risk children: The role of insecure attachment and reassurance seeking. Journal of Clinical Child and Adolescent Psychology. 2005; 34:182-192. [PubMed: 15677292]

Abela JRZ, Zinck S, Kryger S, Zilber I, Hankin BL. Contagious depression: Negative attachment cognitions as a moderator of the temporal association between parental depression and child depression. Journal of Clinical Child and Adolescent Psychology. 2009; 38:16-26. [PubMed: 19130354]

Adler, PA.; Adler, P. Peer power: Preadolescent culture and identity. New Brunswick, NJ: Rutgers University Press; 1998.

Aiken, LS.; West, SG. Multiple regression: Testing and interpreting interactions. Newbury Park, CA: Sage; 1991.

Aloise-Young PA, Graham JW, Hansen WB. Peer influence on smoking initiation during early adolescence: A comparison of group members and group outsiders. Journal of Applied Psychology. 1994; 79:281-287. [PubMed: 8206817]

Bagwell CL, Coie JD, Terry RA, Lochman JE. Peer clique participation and social status in preadolescence. Miller-Palmer Quarterly. 2000; 46:280-305.

Borgatti, SP.; Everett, MG.; Freeman, LC. UCINET for Windows: Software for Social Network Analysis. Cambridge, MA: Analytic Technologies, Harvard; 2002.

Bot SM, Engels RCME, Knibbe RA, Meeus W. Friend's drinking and adolescent alcohol consumption: The moderating role of friendship characteristics. Addictive Behavior. 2005; 30:929947.

Brechwald WA, Prinstein MJ. Beyond homophily: A decade of advances in understanding peer influence processes. Journal of Research on Adolescence. 2011; 21:166-179.

Brown, BB. Peer groups and peer cultures. In: Feldman, SS.; Elliott, GR., editors. At the threshold: The developing adolescent. Cambridge, MA: Harvard University Press; 1990.

Brown BB, Clasen DR, Eicher SA. Perceptions of peer pressure, peer conformity dispositions, and self-reported behavior among adolescents. Developmental Psychology. 1986; 22:521-530.

Brown BB, Eicher SE, Petrie S. The importance of peer group ("crowd") affiliation in adolescence. Journal of Adolescence. 1986; 9:73-96. [PubMed: 3700780]

Buhrmester D. Intimacy of friendship, interpersonal competence, and adjustment during preadolescence and adolescence. Child Development. 1990; 61:1101-1111. [PubMed: 2209180]

Buhrmester D, Furman W. The development of companionship and intimacy. Child Development. 1987; 58:1101-1113. [PubMed: 3608659]

Burk WJ, Steglich CEG, Snijders TAB. Beyond dyadic interdependence: Actor-oriented models for co-evolving social networks and individual behaviors. International Journal of Behavioral Development. 2007; 31:397-404.

Cacioppo JT, Fowler JH, Christakis NA. Alone in the crowd: The structure and spread of loneliness in a large social network. Journal of Personality and Social Psychology. 2009; 97:977-991. [PubMed: 19968414]

Cairns RB, Leung MC, Buchanan LD, Cairns BD. Friendships and social networks in children and adolescents: Fluidity, reliability, and interrelations. Child Development. 1995; 66:1330-1345. [PubMed: 7555219]

Cohen GL, Prinstein MJ. Peer contagion of aggression and health-risk behavior among adolescent males: An experimental investigation of effects on public conduct and private attitudes. Child Development. 2006; 77:967-983. [PubMed: 16942500]

Cole DA, Carpentieri S. Social status and the comorbidity of child depression and conduct disorder. Journal of Consulting and Clinical Psychology. 1990; 58:748-757. [PubMed: 2292624]

Corsaro W, Eder D. Children's peer cultures. Annual Review of Sociology. 1990; 16:197-220.

Coyne JC. Depression and the response of others. Journal of Abnormal Psychology. 1976a; 85:186193. [PubMed: 1254779] 
Coyne JC. Toward an interactional description of depression. Psychiatry. 1976b; 39:28-40. [PubMed: 1257353]

Crandall CS. Social socialization of binge eating. Journal of Personality and Social Psychology. 1988; 55:588-598. [PubMed: 3193348]

Dawber, TR. The Framingham Study. Cambridge, MA: Harvard University Press; 1980.

Degirmencioglu SM, Urberg KA, Tolson JM, Richard P. Adolescent friendship networks: Continuity and change over the school year. Merrill-Palmer Quarterly. 1998; 44:313-337.

Eder D. The cycles of popularity: Interpersonal relations among female adolescents. Sociology of Education. 1985; 58:154-165.

Ellis WE, Zarbatany L. Peer group status as a moderator of group influence on children's deviant, aggressive, and prosocial behavior. Child Development. 2007; 78:1240-1254. [PubMed: 17650136]

Everett MG, Borgatti SP. Analyzing clique overlap. Connections. 1998; 21:49-61.

Furman W, Buhrmester D. Age and sex differences in perceptions of networks of personal relationships. Child Development. 1992; 63:103-115. [PubMed: 1551320]

Gifford-Smith M, Dodge KA, Dishion TJ, McCord J. Peer influence in children and adolescents: Crossing the bridge from developmental to intervention science. Journal of Abnormal Child Psychology. 2005; 33:255-265. [PubMed: 15957555]

Giletta M, Scholte RHJ, Burk WJ, Engels RCME, Larsen JK, Prinstein MJ, Ciairano S. Similarity in depressive symptoms in adolescents' friendship dyads: Selection or socialization. Developmental Psychology. in press.

Hammen C. Cognition, life stress, and interpersonal approaches to a developmental psychopathology model of depression. Development and Psychopathology. 1992; 4:189-206.

Hammen C, Burge D, Adrian C. Timing of mother and child depression in a longitudinal study of children at risk. Journal of Consulting and Clinical Psychology. 1991; 59:341-345. [PubMed: 2030197]

Hammen CL, Peters SD. Interpersonal consequences of depression: Responses to men and women enacting a depressed role. Journal of Abnormal Psychology. 1978; 87:322-332. [PubMed: 681603]

Hankin BL, Abramson LY. Development of gender differences in depression: An elaborated cognitive vulnerability-transactional stress theory. Psychological Bulletin. 2001; 127:773-796. [PubMed: 11726071]

Hankin BL, Abramson LY, Moffitt TE, Silva PA, McGee R, Angell KE. Development of depression from preadolescence to young adulthood: Emerging gender differences in a 10-year longitudinal study. Journal of Abnormal Psychology. 1998; 107:128-140. [PubMed: 9505045]

Hankin BL, Mermelstein R, Roesch L. Sex differences in adolescent depression: Stress exposure and reactivity models in interpersonal and achievement contextual domains. Child Development. 2007; 78:279-295. [PubMed: 17328705]

Hanneman, RA.; Riddle, M. Introduction to social network methods. Riverside, CA: University of California, Riverside; 2005.

Harter, S. Causes, correlates and the functional role of global self-worth: A life-span perspective. In: Kolligian, J.; Sternberg, R., editors. Perceptions of competence and incompetence across the lifespan. New Haven, CT: Yale University Press; 1990. p. 67-98.

Harter S, Stocker C, Robinson NS. The perceived directionality of the link between approval and selfworth. Journal of Research on Adolescence. 1996; 6:285-308.

Hartup WW. The company they keep: Friendships and their developmental significance. Child Development. 1996; 67:1-13. [PubMed: 8605821]

Hogue A, Steinberg L. Homophily of Internalized Distress in Adolescent Peer Groups. Developmental Psychology. 1995; 31(6):897-906.

Hutchinson DM, Rapee RM. Do friends share similar body image and eating problems? The role of social networks and peer influences in early adolescence. Behavior Research and Therapy. 2007; 45:1557-1577. 
Joiner TE Jr. The price of soliciting and receiving negative feedback: Self-verification theory as a vulnerability to depression theory. Journal of Abnormal Psychology. 1995; 104:364-372. [PubMed: 7790638]

Joiner TE Jr. A test of the interpersonal theory of depression in youth psychiatric inpatients. Journal of Abnormal Child Psychology. 1999; 27:77-85. [PubMed: 10197408]

Joiner, TE., Jr; Coyne, J., editors. The interactional nature of depression. Washington, DC: American Psychological Association; 1999.

Joiner TE Jr, Katz J. Contagion of depressive symptoms and mood: Meta-analytic review and explanations from cognitive, behavioral, and interpersonal viewpoint. Clinical Psychology Science and Practice. 1999; 6:149-164.

Kandel DB. Homophily, selection, and socialization in adolescent friendships. American Journal of Sociology. 1978; 84:427-436.

Kazdin, AE. Assessment of childhood depression. In: La Greca, AM., editor. Through the eyes of the child: Obtaining self-reports from children and adolescents. Boston, MA: Allyn \& Bacon; 1990. p. 189-233.

Kovacs, M. Children's Depression Inventory Manual. North Tonawanda, NY: Multi-Health Systems; 1992.

Lansford JE, Costanzo PR, Grimes C, Putallaz M, Miller S, Malone PS. Social network centrality and leadership status: Links with problem behaviors and tests of gender differences. Merrill-Palmer Quarterly. 2009; 55:1-25. [PubMed: 19763241]

Larson RW, Richards MH, Moneta G, Holmbeck G, Duckett E. Changes in adolescents' daily interactions with their families from ages 10 to 18: Disengagement and transformation. Developmental Psychopathology. 1996; 32:744-754.

Marks T, Hammen CL. Interpersonal mood induction: Situational and individual determinants. Motivation and Emotion. 1982; 6:387-399.

Miller-Johnson, S.; Costanzo, P. If you can't beat them. induce them to join you: Peer based interventions during adolescence. In: Kupersmidt, JB.; Dodge, KA., editors. Children's peer relations from development to intervention. Washington, DC: American Psychological Association; 2004. p. 209

Mounts NS, Steinberg L. An ecological analysis of peer influence on adolescent grade point average and drug use. Developmental Psychology. 1995; 31:915-922.

Muthén, B.; Asparouhov, T. Modeling interactions between latent and observed continuous variables using maximum-likelihood estimation in Mplus. 2003. Retrieved from http://www.statmodel.com/download/webnotes/webnote6.pdf

Paxton SJ, Schutz HK, Wertheim EH, Muir SL. Friendship clique and peer influences on body image concerns, dietary restraint, extreme weight-loss behaviors, and being eating in adolescent girls. Journal of Abnormal Psychology. 1999; 108:255-266. [PubMed: 10369035]

Poelen EAP, Engels RCME, Van der Vorst H, Scholte RHJ, Vermulst AA. Best friends and alcohol consumption in adolescence: A within-family analysis. Drug and Alcohol Dependence. 2007; 88:163-173. [PubMed: 17127016]

Potthoff RF, Tudor GE, Pieper KS, Hasselblad V. Can one assess whether missing data are missing at random in medical studies? Statistical Methods in Medical Research. 2006; 15:213-234. [PubMed: 16768297]

Prinstein MJ. Moderators of peer contagion: A longitudinal examination of depression socialization between adolescents and their best friends. Journal of Clinical Child and Adolescent Psychology. 2007; 36:159-170. [PubMed: 17484689]

Prinstein MJ, Aikins JW. Cognitive moderators of the longitudinal association between peer rejection and adolescent depressive symptoms. Journal of Abnormal Child Psychology. 2004; 32:147-158. [PubMed: 15164857]

Prinstein MJ, Borelli JL, Cheah CSL, Simon VA, Aikins JW. Adolescent girls' interpersonal vulnerability to depressive symptoms: A longitudinal examination of reassurance-seeking in peer relationships. Journal of Abnormal Psychology. 2005; 114:676-688. [PubMed: 16351388] 
Prinstein MJ, Cheah CSL, Guyer AE. Peer victimization, cue interpretation, and internalizing symptoms: Preliminary concurrent and longitudinal findings for children and adolescents. Journal of Clinical Child \& Adolescent Psychology. 2005; 34:11-24. [PubMed: 15677277]

Prinstein, MJ.; Dodge, KA. Peer influence processes among youth. New York, NY: Guilford; 2008.

Prinstein MJ, Wang SS. False consensus and adolescent peer socialization: Examining discrepancies between perceptions and actual reported levels of friends' deviant and health risk behaviors. Journal of Abnormal Child Psychology. 2005; 33:293-306. [PubMed: 15957558]

Radke-Yarrow M, Nottelman E, Belmont B, Welsh JD. Affective interactions of depressed and nondepressed mothers and their children. Journal of Abnormal Child Psychology. 1993; 21:683695. [PubMed: 8126320]

Raudenbush, SW.; Bryk, AS. Hierarchical linear models: Applications and data analysis methods. 2nd ed.. Thousand Oaks, CA: Sage Publications; 2002.

Raudenbush, SW.; Bryk, AS.; Cheong, YF.; Congdon, R. HLM 6: Hierarchical linear and nonlinear modeling. Lincolnwood, IL: Scientific Software International Inc; 2004.

Rodkin P, Ahn H. Social networks derived from affiliations and friendships, multi-informant and selfreports: Stability, concordance, placement of aggressive and unpopular children, and centrality. Social Development. 2009; 18:556-576.

Rose AJ. Co-rumination in the friendships of girls and boys. Child Development. 2002; 73:1830-1843. [PubMed: 12487497]

Rose AJ, Carlson W, Waller EM. Prospective associations of co-rumination with friendship and emotional adjustment: Considering the socioemotional trade-offs of corumination. Developmental Psychology. 2007; 43:1019-1031. [PubMed: 17605532]

Rosenquist JN, Fowler JH, Christakis NA. Social network determinants of depression. Molecular Psychiatry. 2010

Rudolph KD. Gender differences in emotional responses to interpersonal stress during adolescence. Journal of Adolescent Health. 2002; 30:3-13. [PubMed: 11943569]

Rudolph, KD.; Flynn, M.; Abaied, JL. A developmental perspective on interpersonal theories of youth depression. In: Abela, JRZ.; Hankin, BL., editors. Handbook of depression in children and adolescents. New York, NY: Guilford Press; 2008. p. 79-102.

Rudolph KD, Hammen C. Age and gender as determinants of stress exposure, generation, and reactions in youngsters: A transactional perspective. Child Development. 1999; 70:66-677.

Saylor CE, Finch AJ, Spirito A, Bennett B. The Children's Depression Inventory: A systematic evaluation of psychometric properties. Journal of Consulting \& Clinical Psychology. 1984; 52:955-967. [PubMed: 6520288]

Shih JH, Eberhart NK, Hammen CL. Differential exposure and reactivity to interpersonal stress predict sex differences in adolescent depression. Journal of Clinical Child and Adolescent Psychology. 2006; 35:103-115. [PubMed: 16390306]

Snijders TAB. The statistical evaluation of social network dynamics. Sociological Methodology. 2001; 31:361-395.

Snijders, TAB.; Bosker, RJ. Multilevel analysis: An introduction to basic and advanced multilevel modeling. London, England: Sage; 1999.

Steinberg L, Monahan KC. Age differences in resistance to peer influence. Developmental Psychology. 2007; 43:1531-1543. [PubMed: 18020830]

Steinberg L, Silverberg SB. The vicissitudes of autonomy in early adolescence. Child Development. 1986; 57:841-851. [PubMed: 3757604]

Stevens EA, Prinstein MJ. Peer contagion of depressogenic attributional styles among adolescents: A longitudinal study. Journal of Abnormal Child Psychology. 2005; 33:25-37. [PubMed: 15759589]

Swann WB Jr, Wenzlaff RM, Tafarodi RW. Depression and the search for negative evaluations: More evidence of the role of self-verification strivings. Journal of Abnormal Psychology. 1992; 101:314-317. [PubMed: 1583225]

Twenge JM, Nolen-Hoeksema S. Age, gender, race, socioeconomic status, and birth cohort differences on the Children's Depression Inventory: A meta-analysis. Journal of Abnormal Psychology. 2002; 111:578-588. [PubMed: 12428771] 
Urberg KA, Degirmencioglu SM, Tolson JM, Halliday-Scher K. The structure of adolescent peer networks. Developmental Psychology. 1995; 31:540-547.

Urberg KA, Luo Q, Pilgrim C, Degirmencioglu SM. A two-stage model of peer influence in adolescent substance use: Individual and relationship-specific differences in susceptibility to influence. Addictive Behaviors. 2003; 28:1243-1256. [PubMed: 12915166]

Van Zalk MHW, Branje SJT, Stattin H, Meeus WHJ. It takes three: Selection, influence, and deselection processes of depression in adolescent friendship networks. Developmental Psychology. 2010; 46:927-938. [PubMed: 20604612]

Vitaro F, Brendgen M, Tremblay R. Influence of deviant friends on delinquency: Searching for moderator variables. Journal of Abnormal Child Psychology. 2000; 28:313-325. [PubMed: 10949957]

Wasserman, S.; Faust, K. Social network analysis: Methods and applications. Cambridge, NY: Cambridge University Press; 1994.

Zakriski AL, Coie JD. A comparison of aggressive-rejected and nonaggressive-rejected children's interpretation of self-directed and other-directed rejection. Child Development. 1996; 67:10481070. [PubMed: 8706509] 

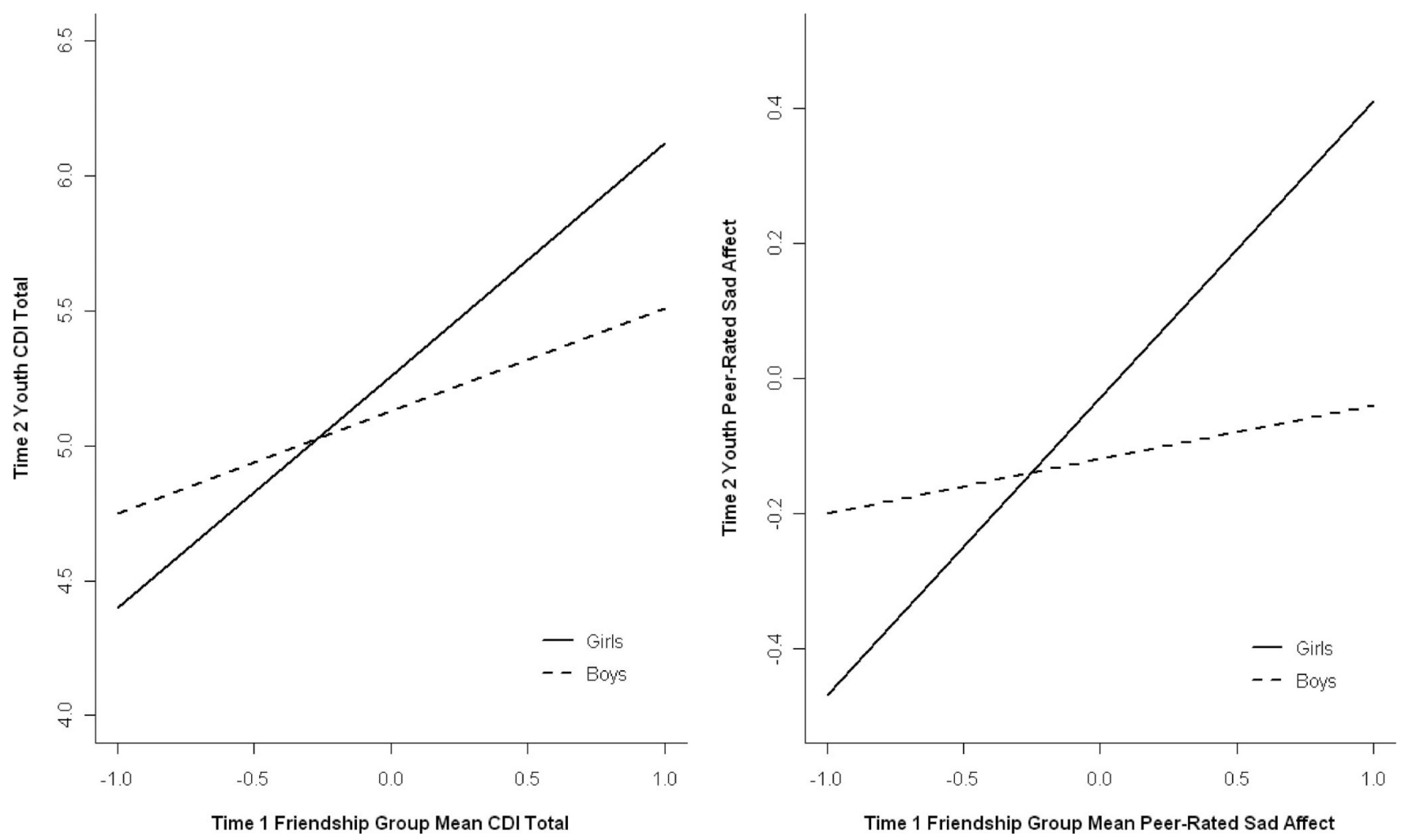

Figure 1.

Interaction of gender and friendship group depressive symptoms at Time 1 in predicting youths' depressive symptoms at Time 2. For ease of interpretation, the $X$-axis of the CDI model is standardized. CDI = Children's Depression Inventory. 

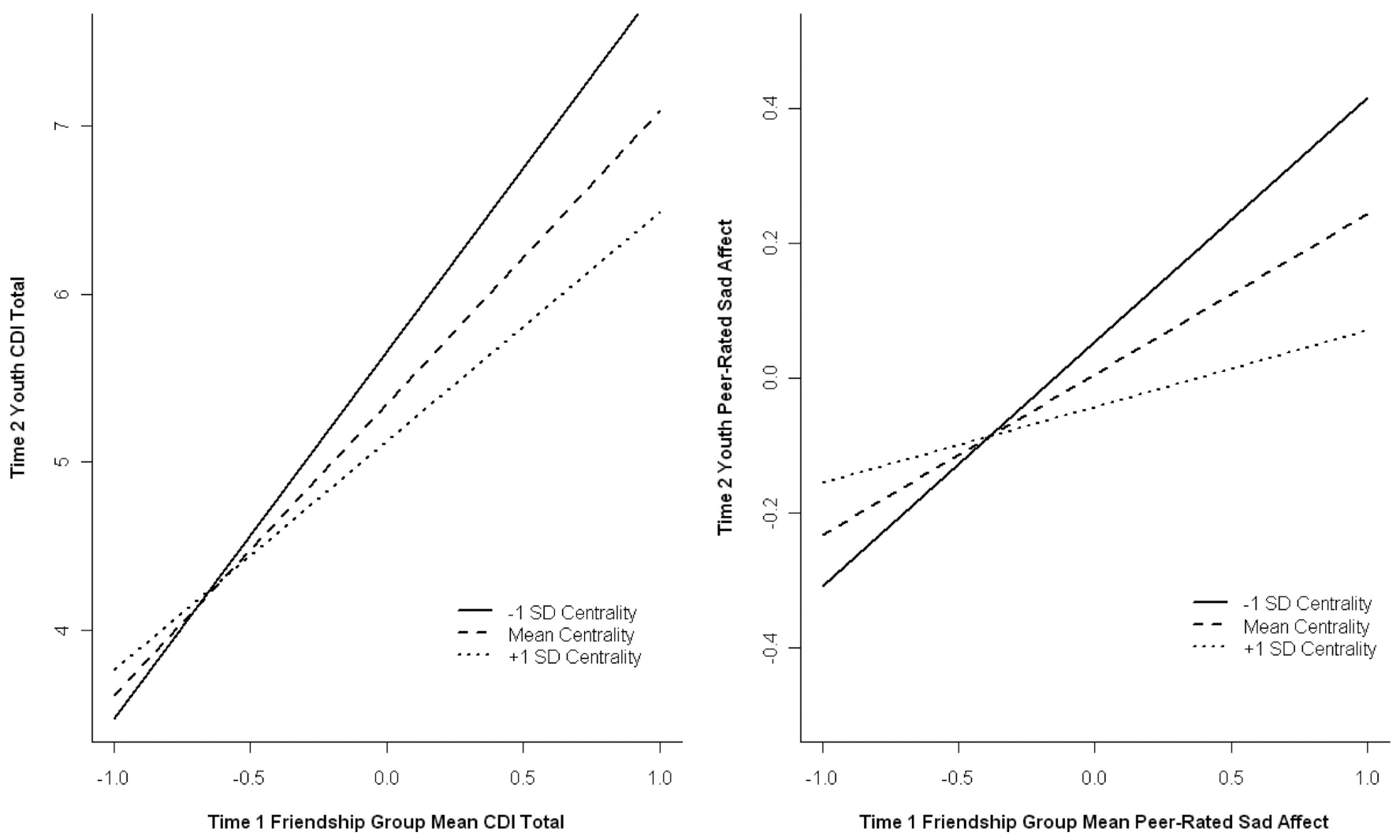

Figure 2.

Interaction of centrality within the friendship group and friendship group depressive symptoms at Time 1 in predicting youths' depressive symptoms at Time 2. For ease of interpretation, the $x$-axis of the CDI model is standardized. CDI = Children's Depression Inventory. 


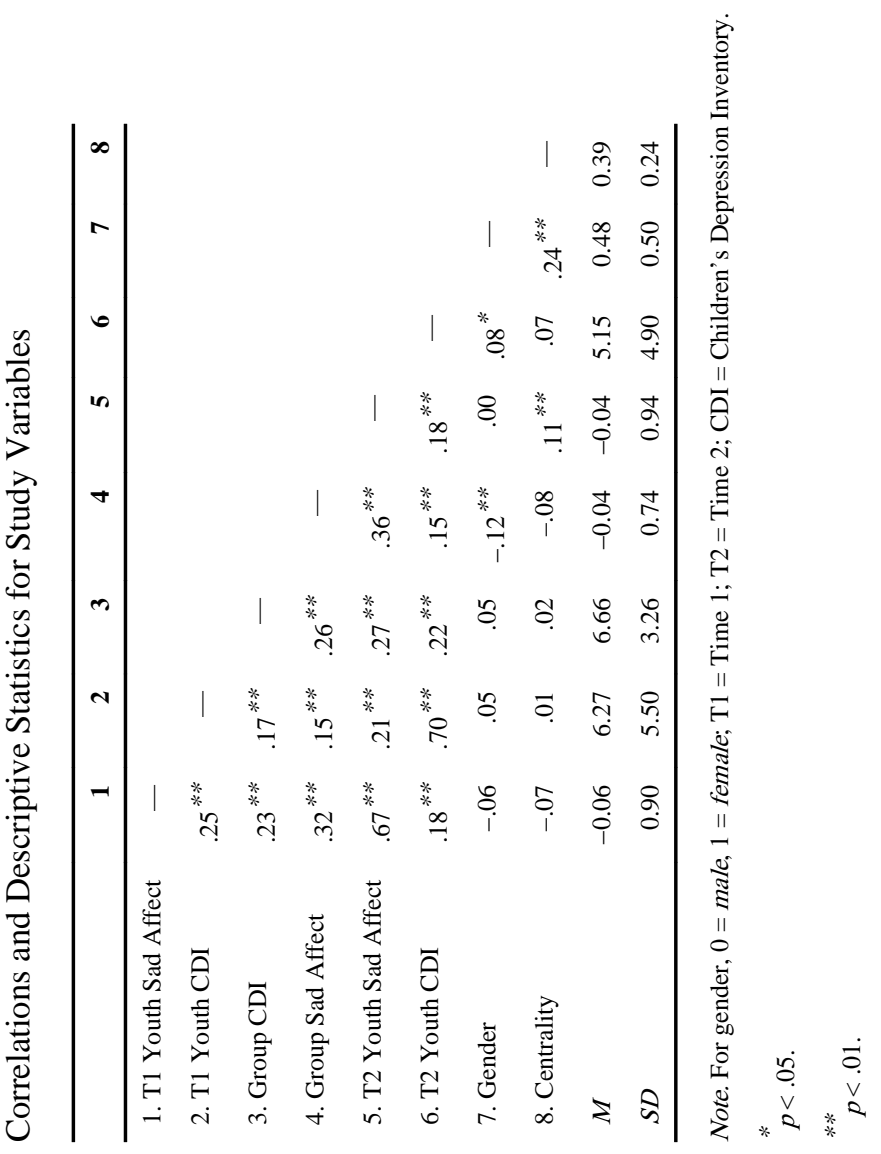

J Abnorm Psychol. Author manuscript; available in PMC 2012 May 16. 